\title{
JEAN GIONO E A REINVENÇÃO DA ODISSEIA NA LITERATURA FRANCESA DO PÓS-GUERRA
}

\author{
Jean Giono and the reinvention of the Odyssey in \\ the French postwar literature
}

\author{
Lorena Lopes da Costa*
}

\begin{abstract}
RESUMO
$\mathrm{O}$ artigo busca analisar a relação entre guerra, experiência e ficção a partir de Naissance de l'Odyssée, uma releitura francesa da Odisseia. Jean Giono (1895 - 1970), em retorno da Guerra de 1914, escolhe a poesia épica como suporte para elaborar os desafios vividos e para pôr em xeque a tradição. As fontes utilizadas na discussão são a literatura de Giono, em especial Naissance de l'Odyssée, romance publicado em 1930, bem como seus escritos de guerra e correspondências.
\end{abstract}

Palavras-chave: Grande Guerra; França; Jean Giono; Odisseia.

\begin{abstract}
This paper aims to analyze the relation between war, experience and fiction, through Naissance de l'Odyssée, a French rewriting of the Odyssey. Jean Giono (1895 - 1970), in return from The Great War, chooses epic poetry as a support to elaborate the challenges of the conflit and to put the tradition into question. The sources are Giono's literature, in particular Naissance de l'Odyssée, novel published in 1930, as well as his war writings and correspondence.
\end{abstract}

Keywords: The Great War; France; Jean Giono; Odyssey.

* Professora de Teoria da História na Universidade Federal do Oeste do Pará (UFOPA). Doutora em História pela UFMG, bolsista Capes, sob orientação do Prof. Dr. Dabdab Trabulsi. 


\section{Introdução}

Em prefácio de Naissance de l'Odyssée [Nascimento da Odisseia], para a segunda edição do livro, de 1960 ("Préface à l'édition de 1960" ["Prefácio à edição de 1960"]), o autor francês Jean Giono (1895 - 1970) descreve o processo de criação que lhe teria dado origem. As memórias de Giono dos primeiros anos que se seguem à Grande Guerra não apenas confirmam o destino preferido dessa evasão, que é o mundo de Odisseu, como o justificam pela insistência de tais memórias. Depois de servir na guerra, durante mais de quatro anos e, em dois deles, ter combatido no front francês, Giono teria passado a dividir o tempo do trabalho com o tempo da escrita de seu primeiro romance: "Acredita-se que sair de uma guerra para ficar trancafiado dentro de um porão não é uma sorte invejável, ao contrário", diz Giono.

Eu ganhava duzentos e quarenta francos por mês, minha pensão num restaurante me custava duzentos francos e meu quarto oitenta; para dar conta de tudo, eu tinha que compartilhar esse quarto com um colega que estava na mesma situação que eu. Nós colocávamos um colchão no chão e dormíamos, cada um conforme seu turno, uma semana sobre o colchão, uma semana sobre o estrado. Era perfeito. A guerra tem essa vantagem: ela faz você achar bonito tudo o que não é guerra. (GIONO, 1971, p. $845-846)^{1}$

Para conseguir voltar da guerra, Giono recorreria à Odisseia . De seu nostos, o resultado será, em 1924, uma primeira versão de

1 Texto original: On croit que sortir de la guerre pour être enfermé dans une cave n'est pas un sort enviable; au contraire. (...) Je gagnais deux cents quarante francs par mois, ma pension dans un restaurant me coûtait deux cents francs et ma chambre quatre-vingts; pour y arriver je devais donc partager cette chambre avec un collègue qui était dans la même situation que moi. Nous mettions le matelas par terre et nous couchions, chacun à notre tour, une semaine sur le matelas, une semaine sur le sommier. C'était parfait. La guerre a cet avantage qu'elle vous fait trouver magnifique tout ce qui n'est pas la guerre. 
Naissance de l'Odyssée. O livro teria sido escrito num subsolo. Giono é desmobilizado em 1919. Seu posto no banco em que trabalhara, em sua cidade natal, antes de partir para o front, havia sido ocupado por uma mulher e o banco oferece-lhe, então, um lugar na agência de Marseille. De volta ao trabalho, Giono passa a ser o encarregado da conservação dos títulos, que se conservavam nos cofres, que, por sua vez, se conservavam no subsolo. Seria no subsolo, portanto, que ele dividiria o tempo do trabalho com o tempo da escrita de Naissance de l'Odyssée. E, se durante a semana seu refúgio é o subterrâneo do banco, onde reencontraria o prazer de criação literária, atualizando a sua Odisseia, aos fins de semana, embora seu refúgio mude de lugar, seu enredo continuaria sendo a história de Odisseu.

O resto da semana então, ao mesmo tempo em que eu "conservava", eu imaginava as aventuras de Odisseu à minha maneira, com os meios que eu dispunha. Eu tinha uma gaveta, e nessa gaveta, meu manuscrito. Com um ouvido eu vigiava na escada o passo do chefe da seção, com o outro eu escutava os rumores do mar na concha de imagens colhidas no domingo anterior. Ao menor barulho de botas no chão, eu fechava a gaveta, mas, na calmaria, eu a abria. Nenhum subterrâneo resiste a essa manobra. (GIONO, 1971, p. 845-846) ${ }^{2}$

No prefácio original do romance para as Edições Kra ["Préface à l'édition originale"], responsáveis pela publicação original da obra em 1930, Jean Giono explica, pela primeira vez de forma direta, a relação que teriam para si a Odisseia, a Grande Guerra e a criação literária. Em 1920, um ano depois de ser desmobilizado, ele

2 Texto original: Le reste de la semaine donc, en même temps que je "conservais", j'imaginais les aventures d'Ulysse à ma façon, avec les moyens du bord. J'avais un tiroir, et dans ce tiroir mon manuscrit. D'une oreille je guettais dans l'escalier le pas du chef de service, de l'autre j'écoutais les grondements de la mer dans la coquille d'images récoltées le dimanche précédent. Au moindre bruit de bottines craquantes je fermais le tiroir, mais, au calme, je l'ouvrais. Aucun souterrain ne résiste à cette manoeuvre. 
não tinha mais do que uma Bíblia, uma pensão irrisória que recebia em função do ferimento que a guerra lhe causara e uma Odisseia (GIONO, 1971, p. 843).

Um dia que eu passava a tarde de domingo na casa de amigos do interior, deixei por um instante o livro sobre a mesa para poder olhar os porcos. Quando voltei, o senhor havia colocado seus óculos e lia movendo silenciosamente seus grossos lábios. Depois de um pouco, ele abaixou o livro, me olhou por cima de suas lentes:

"Este aqui é seu?" ele me disse.

Eu disse sim.

"Bem, isso sim é um livro - ele disse - isso sim! Não essa água com açúcar de romance que vem no jornal."

Eu tinha chegado à fazenda de Odisseu. (GIONO, 1971, p. $843-4)^{3}$

$\mathrm{O}$ autor de Manosque, cidade provençal, ao menos com relação à Antiguidade, teria sido um autodidata. ${ }^{4}$ No liceu, que frequentou por poucos anos, entre 1902 e 1911, não estudou nem grego nem latim. E mesmo a prematura interrupção de seus estudos não fora capaz de interromper seu contato com a literatura clássica.

Eu recebia dois francos por domingo. Eu tinha receio, mas eu os gastava. Os livros da edição Anatole France custavam três francos e cinqüenta na livraria CalmannLevy. Eurípedes, Ésquilo, Sófocles, Aristófanes, Virgílio custavam 0,95 na Classiques Garnier. Com meus dois

3 Texto original: Un jour que je passais un après-midi de dimanche chez des amis de la campagne, je laissais un moment le livre sur la table pour m'en aller regarder les porcs. Quand je revins, le maître avait mis ses lunettes et lisait en bougeant sans bruit ses grosses lèvres. Au bout d'un peu il abaissa le livre, me regarda par-dessus ses verres:/ "C'est à toi, ça", il me dit?/ Je dis oui./"Eh bien, ça c'est des livres, il fit; ça oui! Non pas ces bonbonnailles de romans du journal. J'étais arrivé dans la ferme d'Ulysse."

4 A partir das entrevistas que faz em 1969 com Jean Giono, Pierre Citron afirma que, muito provavelmente, o autor não teria lido Elpénor, obra de Jean Giraudoux, aproximável de sua Naissance de l'Odyssée, uma vez que ambas realizam uma releitura da Odisseia, desconstruindo o herói. 
francos, eu tinha dois desses autores e ainda me restavam duas moedas. Com elas, eu selava minha carta, pois como não havia livrarias em Manosque, eu encomendava diretamente de Paris. (GIONO, 1971, p. 833) ${ }^{5}$

Ainda assim, os registros do autor acerca de sua recriação odisseica apontam para uma espécie de desconfiança do resultado, motivada pelo que ele identifica como, por um lado, um excesso de imaginação e, por outro, uma insuficiência de informação. Giono hesitaria, destarte, em finalizar o romance, faria seus escritos ganharem novos personagens, bem como novas fontes de pesquisa e diálogo. A correspondência com o amigo e poeta Lucien Jacques, que tem início em 1924, mostra claramente que Naissance de l'Odyssée fora um longo trabalho: mais de dois anos e meio de criação, um prólogo três vezes refeito, episódios suprimidos, os dois primeiros terços inteiramente reescritos, uma reorganização do conjunto em 1927 e inúmeras correções (CITRON, 1971; ONIMUS, 1974).

Em carta para o amigo Lucien Jacques, datada de 11 de janeiro de 1925, Jean Giono diz sobre a dispendiosa aquisição que havia feito. Além da tradução da Odisseia feita por Victor Bérard, que Jean Giono obtém pelo alto preço de 150 francos, o autor trata também de comprar os três volumes que servem de introdução à tradução. A partir de então, tanto a nova tradução quanto o estudo passam a ser companhias permanentes do autor. Ele leria até mesmo De l'origine des cultes arcadiens, de Bérard, sobre o qual registra: "No meio da semana passada, eu disse a mim mesmo: 'Meu velho Giono, se você não o abandonar aí imediatamente, você vai morrer"' (GIONO apud CITRON, 1971, p. 829) . $^{6}$

Sua dúvida sobre estar seu romance distante demais do universo odisseico não o permite desistir de Bérard, por mais

5 Texto original: Je recevais deux francs par dimanche. J'avais scrupule, mais je les prenais. Les Anatole France coûtaient trois francs cinquante chez Calmann-Lévy. Euripide, Eschyle, Sophocle, Aristophane, Virgile coûtaient 0,95 dans les Classiques Garnier. Avec mes deux francs, j'avais deux de ces gens-là et il me restait deux sous. Avec les deux sous je timbrais ma lettre, car il n'y avait pas de librairies à Manosque et je commandais directement à Paris.

6 Texto original: $A$ un détour de la semaine passée je me suis dit: "Mon vieux Giono si tu ne sors pas de là tout de suite tu vas te crever". 
fatigante que seja a leitura de seus estudos. As novas leituras, realizadas no ano de 1927, acalmam-no um pouco o espírito. A partir das novas referências, o que inclui então a tradução de Bérard da Odisseia, seus estudos introdutórios ao poema, Les Navigations d'Ulysse [As navegações de Odisseu], Les Phéniciens et l'Odyssée [Os Fenícios e a Odisseia] e De l'origine des cultes arcadiens [Da origem dos cultos arcádios], Giono comemora, ainda em carta ao amigo, não ter cometido muitos erros.

\section{A experiência de Jean Giono no front: a guerra como um triturador de grãos}

O livro que Giono teria escrito no subterrâneo do banco, logo depois de sua volta da guerra, conta também a história daquele que volta da guerra. O Odisseu de Giono é um camponês astuto e fanfarrão, dono de uma imaginação fértil em aventuras fabulosas, hábil contador de histórias que, tal como o Odisseu de Homero, faz uso de sua habilidade para retornar à pátria. Como sintetiza Suzanne Saïd, no texto de Giono, a guerra de Troia com suas trincheiras guarda, sem dúvida, uma forte semelhança com a guerra de 1914 (SAÏD, 2003).

Não obstante, é comum ler na fortuna crítica sobre a obra de Jean Giono que o autor evocaria a Grande Guerra apenas em 1931, quando é publicado Le Grand Troupeau [O Grande Rebanho], romance que opõe dois mundos, o da paz provençal ao do horror das trincheiras, de maneira explícita. Naissance de l'Odyssée (cuja primeira versão data de 1924 e a primeira publicação de 1930); porém, ainda que não seja um romance farto em imagens de guerra, põe em xeque tal asserção. O texto "Refus d'obéissance", publicado pela Gallimard em Écrits pacifistes [Escritos pacifistas], em 1937, é uma evidência do quanto Naissance de l'Odyssée evocaria, porque era inevitável, ao autor, a guerra. 
Eu não posso esquecer a guerra. Eu bem que gostaria. Passo às vezes dois dias ou três sem pensar nela e, de repente, eu a vejo, eu a sinto, eu a escuto, eu ainda sofro. E tenho medo. Esta noite é o fim de um belo dia de verão em julho. A grama em que piso ficou toda avermelhada. Vamos cortar o trigo. $\mathrm{O}$ ar, o céu e a terra ainda estão imóveis e calmos. Vinte anos se passaram. E por vinte anos, apesar da vida, da dor e da felicidade, eu não consegui me limpar da guerra. O horror desses quatro anos ainda está em mim. Eu tenho uma cicatriz. Todos os sobreviventes têm uma cicatriz. (GIONO, 2015, p. 15) ${ }^{7}$

Em 1915, Jean Giono parte para o front. Ao longo da guerra, ele afirma não ter sido nunca ferido, a não ser pelas queimaduras nas pálpebras por gás em Kammel (que, segundo ele em seus Écrits pacifistes [Escritos pacifistas], renderam-lhe em 1920 a já mencionada pensão de quinze francos a cada três meses sob a justificativa "Léger déchet esthétique", GIONO, 2015, p. 16). O episódio, aliás, parece ser rememorado no capítulo "Bataille du Kemmel", não publicado em Le Grand Troupeau [O Grande Rebanho], mas apenas posteriormente, ao lado de outros três capítulos excluídos do romance, nos Écrits Pacifistes: “[...] Antes de sair, o inglês veste sua máscara. - Gás. Ele aponta para o monte Kemmel, depois ele desenha no céu com seu dedo o caminho por onde vem o gás" (GIONO, 2015, p. 99). ${ }^{8}$ Em Naissance de l'Odyssée, em que a fadiga e a dor do corpo são aludidas frequentemente ao longo do retorno de Odisseu, destaca-se, exatamente, a alusão às pálpebras, lembradas desde os primeiros parágrafos, quando o Odisseu de Giono, ao salvar-se do naufrágio que o faz aportar na ilha de Circe, "não mandava senão em suas pálpebras e elas estavam abertas sob a

7 Texto original: Je ne peux pas oublier la guerre. Je le voudrais. Je passe des fois deux jours ou trois sans y penser et brusquement, je la revois, je la sens, je l'entends, je la subis encore. Et j'ai peur. Ce soir est la fin d'un beau jour de juillet. La plaine sous moi est devenue toute rousse. On va couper les blés. L'air, le ciel, la terre sont immobiles et calmes. Vingt ans ont passé. Et depuis vingt ans, malgré la vie, les douleurs et les bonheurs, je ne me suis pas lavé de la guerre. L'horreur de ces quatre ans est toujours en moi. Je porte la marque. Tous les survivants portent la marquent.

8 Texto original: Avant de partir, l'Anglais tape sur le sac à masque. - Gaz. Il montre le Kemmel, puis il dessine dans le ciel avec son doigt le chemin par où viennent les gaz. 
desolação do céu" (GIONO, 1938, p. 11). ${ }^{9}$ Único lugar do corpo em que Giono havia sido ferido e cujo ferimento é motivo de sua ironia, o autor não teria eleito as pálpebras para sinalizar, repetidas vezes, o sofrimento do guerreiro a caminho de casa coincidentemente. Em Le Grand Troupeau, delas também não se esquecem os ratos: "Eles começavam pelos olhos, com pequenos golpes de garras, lambiam o buraco das pálpebras, depois mordiam o olho, como se mordessem um pequeno ovo, e então o mastigavam lentamente, a boca de lado sorvendo o sumo" (GIONO, 1931, p. 115-116). ${ }^{10}$

Jean Giono, durante os anos de guerra, combate como soldado de segunda classe, na infantaria. Ao lado de seu capitão, ele é dos poucos sobreviventes da sexta companhia, uma pequena reserva da vigésima sétima divisão. Tendo lutado em Epargnes, VerdunVaux, Noyons-Saint-Quentin, Chemin des Dames, Pinon, Chevrillon e Kemmel, o autor, que afirma não ter matado ninguém (GIONO, 2015, p. 16), observa o quanto a morte banalizou-se:

A sexta companhia foi completada com novos homens mil e uma vezes. A sexta companhia era um recipiente da vigésima sétima divisão como um tonel de trigo. Quando o tonel ficava vazio de homens, quando enfim não restava mais do que alguns no fundo, como os grãos que se prendem aos sulcos, enchia-se o tonel de novo com novos homens. Por isso, a sexta companhia foi completada com novos homens mil e uma vezes. E mil vezes foi-se esvaziála no moedor de trigo. (GIONO, 2015, p. 15-6) ${ }^{11}$

9 Texto original: ne commandait plus qu'à ses paupières et elles étaient ouvertes sur la désolation du ciel.

10 Texto original: Pour les yeux, ils les sortaient à petits coups de griffes, et ils léchaient le trou des paupières, puis ils mordaient dans l'oeil, comme dans un petit oeuf, et ils le mâchaient doucement, la bouche de côté en humant le jus.

11 Texto original: La 6ème compagnie a été remplie cent fois et cent fois d'hommes. La bème compagnie était un petit récipient de la 27ème division comme un boisseau à blé. Quand le boisseau était vide d'hommes, enfin quand il n'en restait plus que quelques-uns au fond, comme des grains collés dans les rainures, on le remplissait de nouveau avec des hommes frais. On ainsi rempli la bème compagnie cent fois et cent fois d'hommes. Et cent fois on est allé la vider sous la meule. 
O grão de trigo e seus derivados, como a farinha, são metáforas recorrentes nos escritos de guerra de Giono para se referir à vida humana; também são recorrentes os verbos que traduzem a ação de preencher, encher o triturador de grãos com o trigo. Em geral, o uso da imagem de um compartimento que é preenchido com grãos de trigo (ou esvaziado para ser, em seguida, preenchido) parece querer sinalizar o quanto a vida humana, na guerra, não tem valor. A guerra é também insistentemente apresentada na forma de um moedor de trigo [la meule; un boisseau à blé], que tritura os grãos, extinguindo vidas. Em Giono, o trigo assim simboliza não exatamente a vida, em sua normalidade, ou a vida que se extingue banalmente na guerra, mas o limite entre as duas condições, que, por sua vez, aponta para a fragilidade desse limite mesmo. Em Le Grand Troupeau, quando a guerra eclode e os camponeses jovens precisam partir para o front, sem conhecer a guerra e sem reconhecerem nela a sua guerra: “- Nós não somos da raça dos guerreiros!" (GIONO, 1931, p. 19), ${ }^{12}$ a véspera da partida cheira curiosamente a trigo: "Sim, muito a trigo" (GIONO, 1931, p. 16). ${ }^{13}$ Por causa da guerra, o cheiro de trigo se pronuncia, os animais se movimentam e os homens partem: "eles haviam sido enviados numa grande manada em direção à morte" (GIONO, 1931, p. 122). ${ }^{14}$

Em Refus d'obéissance [Recusa de obediência], texto publicado em 1937, o autor rememora sua partida para o front em 1915, e reconhece, na partida, sua covardia: a covardia de não ter conseguido dizer não à guerra. Ele a identifica, porém, bem mais pronunciada, nos professores, magistrados da República, ministros, que, segundo ele, serviam-se do sangue dos jovens, enganando-os. "Havia também - eu me esquecia deles, mas eles também são muito importantes - os escritores que exaltavam o heroísmo, o egoísmo, o orgulho, a resistência, a honra, a força, a altivez" (GIONO, 2015, p. 18). ${ }^{15}$ Dessa forma, os mais covardes para Giono teriam sido os que

12 Texto original: - On n'est pourtant pas de la race des batailleurs!

13 Texto original: Oui, trop le blé.

14 Texto original: on les avait envoyés en gros troupeau dessus la mort.

15 Texto original: Il y avait aussi - je les oubliais mais ils sont très importants - les écrivains qui exaltaient l'héroïsme, l'égoïsme, la fierté, la dureté, l'honneur, le sport, l'orgueil. Esta é também a crítica que o veterano alemão da Grande Guerra Erich Maria Remarque igualmente faz em seu All Quiet on the Western Front (1929). 
exaltaram tudo aquilo que, ao longo da história ocidental, contribuíra para dar à guerra a imagem de um evento sublime em que o heroísmo, o orgulho, a honra e a valentia faziam valer qualquer esforço e todo sofrimento.

Sobre o retorno da guerra e o retorno em Naissance de l'Odyssée

Os caminhos percorridos pelos combatentes depois dos conflitos são tema de nosso escritor em suas cadernetas de guerra. Após a Batalha de Kemmel, que ocorre de 9 a 25 de abril de 1918, e na qual o autor é ferido em consequências das armas de gás, lê-se em uma delas: "A estrada está como um rio morto. Ela está sob a podridão de carros perfurados, cavalos e homens. Canhão nas trincheiras, metralhadoras, espingardas" (GIONO, 2015, p. 109). ${ }^{16} \mathrm{~A}$ caminhada e suas horas intermináveis, ao menos com o fim da Batalha de Kemmel, ganham a forma da errância. As personagens de Le Grand Troupeau, não raro, se confundem sobre a quantidade de horas ou de dias de marcha ou de espera: "- Ainda é hoje ou já é amanhã?" (GIONO, 2015, p. 121), ${ }^{17}$ pergunta Olivier, um dos combatentes que vive as histórias de guerra, num dos capítulos não publicados. O retorno dos sobreviventes em Le Grand Troupeau se parece com o retorno do Odisseu de Giono. Um dos combatentes, por exemplo, como ele, atravessa a pé "toda essa longa terra ondulada" (GIONO, 1931, p. 184). ${ }^{18}$ Mas entre as vilas e a guerra "há muitas ovelhas mortas pela estrada" (GIONO, 1931, p. 26). ${ }^{19}$ Também a caminho de casa, outra das personagens experimenta o retorno

16 Texto original: La route est comme un ruisseau mort. Elle est sous la pourriture de voitures crevées, de chevaux et d'hommes. Des canons dans les fossés, des mitrailleuses, des fusils.

17 Texto original: - On est toujours aujourd'hui ou bien on est déjà demain?

18 Texto original: toute cette longue terre ondulée.

19 Texto original: c'est plein de moutons morts sur la route. 
enquanto experiência solitária, quando responde a um sargento de passagem: “- Muitos mortos? - Todos..." (GIONO, 1931, p. 242). ${ }^{20}$

Em Naissance de l'Odyssée, o Odisseu de Giono, que erra pelos mares e pelas terras, é um Odisseu sem identidade e sem grandes feitos. O Odisseu de Giono é um camponês amante das mulheres e da natureza, que escolhe não voltar para Ítaca para viver os prazeres do corpo. Toda a história se constrói iluminada pela guerra, a qual, embora poucas vezes aludida, é descrita de forma confusa e anacrônica, fazendo com que Troia ceda lugar às trincheiras.

No enredo, a descrição da vida após a guerra, feita pelo narrador e não por Odisseu, vem acompanhada da notícia, dada por Menelau (que também sofrera o adultério da esposa) de que Penélope traía o Laertíade com Antínoo. O encontro se dá na ilha de Circe (em Naissance de l'Odyssée, chamada Cythère [Citera]); é lá que a história do retorno, de fato, tem início. A notícia da traição é o elemento que faz com que o Odisseu de Giono decida abandonar a vida de prazeres para, enfim, retornar à pátria. Para tanto, ele torna-se um grande mentiroso. Seu primeiro mestre, quem primeiro ensina-lhe a mentir, é Árquias [Archias], o marinheiro e amigo que o acompanha pelas ilhas e pelos mares, o único de seus companheiros a sobreviver à guerra um pouco como o capitão Vidon, que, ao lado de Giono, havia sido o único a sobreviver da sexta companhia: "Eu e M. V., que era meu capitão, fomos mais ou menos os únicos sobreviventes da primeira $6^{\mathrm{a}}$ companhia. [...] Nós somos de tudo aquilo os últimos em vida, V. e eu" (GIONO, 2015, p. 15-16). ${ }^{21}$ Árquias [Archias] também era de Ítaca e sabia que "sem a invasão dos mundos fantásticos, sua cabeça teria se preenchido com as mesmas lembranças que tinha Odisseu" (GIONO, 1938, p. 18). ${ }^{22}$ Em seu retorno, o Odisseu de Giono assemelha-se com o Odisseu de Homero no sentido de que ele mente para disfarçar sua identidade e para dizer que Odisseu retornará. É o que diz, por exemplo, aos homens que dividem com ele a hospedaria onde, depois de ter partido de Citera [Cythère], passa a noite:

20 Texto original: - Beaucoup de morts? - Tous...

21 Texto original: Avec M. V., qui était mon capitaine, nous sommes à peu près les seuls survivants de la première 6e compagnie. [...] Nous sommes de tout ça les derniers vivants, V. et moi.

22 Texto original: sans l'invasion des mondes magiques, sa tête eût été pleine des mêmes souvenirs que celle d'Ulysse. 
- [...]Eu fiz a guerra da Ásia. Eu conheço Odisseu. Quantas vezes, quando a trombeta soava, eu não o vi perseguir os troianos e depois retornar aos navios por último, coberto de um sangue mais espesso do que piche? É certo que eu também pensei que o mar estufado o havia engolido. Agora, porém, eu digo a vocês: uma vez eu o encontrei na ponte de cordas, não sua sombra, mas sua carne sólida, eu o toquei, eu o toquei como toco esta perna, eu falei com ele, ele está vivo! (GIONO, 1938, p. 45) ${ }^{23}$

No caminho do regresso, que liga uma vida de divertimento a Ítaca, Odisseu conhece todos os sofrimentos. Sua pele é machucada pelo sol, a sede lhe devora, ele se perde entre as montanhas, seu corpo conhece as feridas, as praias secam, até mesmo o ar geme de dor (GIONO, 1938, p. 56), ele experimenta novamente o medo, a vingança dos deuses e a tristeza. Ao chegar à Ítaca, o Odisseu de Naissance de l'Odyssée está envelhecido e desgastado. Eumeu, distinto do Eumeu odisseico, sem saber guardar o segredo da chegada de seu mestre, corre a Penélope para lhe contar a novidade. Telêmaco, por sua vez, em nada admira o pai e ressente-se de sua fraqueza para com o rival - Antínoo, o pretendente eleito pela Penélope de Giono -, pois ao propor a Odisseu a morte do amante de sua mãe, Telêmaco escuta do pai recém-chegado: "Sem guerra, sem guerra" (GIONO, 1938 , p. 94). ${ }^{24}$ De volta à casa, Odisseu está, assim, sozinho, não pode contar com ninguém e tampouco sabe enfrentar a realidade.

No caminho, porém, na mesma hospedaria em que dera notícia de que Odisseu regressaria, o Laertíade inventa sua maior mentira. E ela alcança Ítaca muito antes dele mesmo. Sua mentira é o que o protege. Na história inventada, Odisseu porta uma fulgurante espada, tem músculos firmes, perde a conta do número dos inimigos

23 Texto original: - [...] J'ai fait la guerre d'Asie. Je connais Ulysse. Combien de fois, au moment où sonnait la trompette, ne l'ai-je pas vu harceler les dos troyens puis revenir aux vaisseaux le dernier, couvert d'un sang plus épais que la poix? Certes, j'ai cru aussi que la mer étouffeuse l'avait eu. Maintenant, moi je vous dis: je l'ai rencontré naguère au pont des lianes, non pas ombre, mais chair solide, je l'ai touché, touché comme je touche cette jambe, je lui ai parlé, il est vivant!

24 Texto original: Pas de bataille, pas de bataille. 
mortos na guerra e dos monstros enfrentados no retorno. Mas a distância entre o Odisseu real e o Odisseu inventado é grande demais. Não é à toa que, ao vê-lo, Penélope espera por uma súbita transformação, que não acontece. Definitivamente, não é o herói da canção quem chega. Odisseu retorna da guerra, mas não retorna como o herói anunciado pelos ventos. O Odisseu heroico só existe na mentira, nos cantos inventados. $\mathrm{O}$ guerreiro que chega é fraco e pusilânime, não quer nem mesmo enfrentar seu rival. É verdade que o amante de Penélope morrerá, como morrem todos os pretendentes de Penélope na Odisseia. Mas a morte de Antínoo em Naissance de l'Odyssée se dá por acidente. À maneira de Giono, que diz "estou certo de não ter matado ninguém", esse Odisseu, de fato, não quer matar ninguém: "sem guerra, sem guerra".

Como a maior parte das personagens do romance, o Odisseu de Jean Giono pertence a uma humanidade média. Ele é capaz de ser egoísta, a ponto de ser odioso, comenta Pierre Citron (1971). O Odisseu de Giono abandona Árquias [Archias], o marinheiro que lhe fora tão fiel, o único sobrevivente dentre seus companheiros. Ele distingue-se dos outros apenas pelo que inventa de si. O Odisseu de Giono não tem o físico avantajado. Ele tem somente seu "castelo de mentiras", capaz de descrever um herói que inexiste, de modo que, para Corinne Jouanno (2013), ${ }^{25}$ o Odisseu de Giono mais refuta o Odisseu de Homero do que o incorpora.

Ao chegar à Ítaca, incapaz de desafiar o homem que lhe roubara a esposa e os bens, o Odisseu de Giono mata o pássaro que lhe havia reconhecido, canalizando na ação, no fraco corpo de uma ave, o ódio pelo rival:

A pega ${ }^{26}$, que ele havia deixado de acariciar, bicou amorosamente seus dedos. Odisseu retirou a mão como se tivesse tocado fogo. A corvona faria com que fosse reconhecido!

25 Texto original: son édifice de mensonges.

26 A pega [la pie] é uma ave europeia, da família dos corvídeos, de cauda longa, coloração preta, tendendo ao verde no dorso, com flancos, abdômen e baixo dorso brancos, asas azuis e coberteiras primárias verdes. (MORVAN, 2009; HOUAISS, 2001). 


\begin{abstract}
- Ave suja!
Ele então estendeu a mão. Ela deixou-se tomar, piscando os olhos, à espera das carícias.

Ele sentia palpitar aquela pequena bolinha quente, cheia de boas lembranças e de uma fiel afeição, a única que tinha ido em sua direção sem titubear.

Ele tremia quando, do fundo de sua mente, apareceu a imagem de Antínoo, uma montanha de força!

Seus dedos se serraram em volta do pescoço da pega.

Ela deu um pequeno suspiro que rapidamente se acabou: bateu um pouco as asas, lentamente, um pobre velho corpo! Pendurada já sem vida, ele ainda a segurava desesperadamente. (GIONO, 1938, p. 121-2) ${ }^{27}$
\end{abstract}

O episódio é uma irônica transposição do que ocorre com Argos, o fiel cão de Odisseu, que esperou durante vinte anos a chegada de seu dono na Odisseia. Antes da partida do Laertíade para a guerra, Argos fora o cão de belo porte, rápido e forte, de bom faro, não havendo animal no bosque perseguido por ele que dele conseguisse fugir (Od., XVII, v. 312-317). Tal qual a gralha de Naissance de l'Odyssée, Argos, o fiel cão de Odisseu também dá mostras de reconhecê-lo: "Mas quando se apercebeu que Odisseu estava perto, começou a abanar a cauda e baixou as orelhas; só que já não tinha força para se aproximar do dono" (Odisseia, XVII, 301-303, tradução de Frederico Lourenço).

O Odisseu de Homero também o reconhece. Emociona-se e precisa esconder o choro de Eumeu, o porqueiro para quem até então dissimulava a identidade. Argos, pouco depois de rever seu dono, encontra o "negro destino da morte". Ele morre, porém, não pelas mãos de seu dono, que é quem, na versão de Giono, esmaga o pescoço

27 Texto original: La pie qu'il ne caressait plus lui becqueta amoureusement les doigts. Il retira sa main comme s'il avait touché du feu: Margotton allait le faire reconnaître!/ - Sale bête!/ Il étendit la main. Elle se laissa prendre, clignant les yeux sous les caresses espérées./ Il sentait palpiter cette petite boule tiède, pleine de bon souvenir et de fidèle affection, la seule qui se soit avancée sans faillir vers lui./ Il tremblait quand, précise, devant la caverne de sa tête, apparut l'image d'Antinoüs, une montagne de force!/ Ses doigts se serrèrent sur le cou de la pie./ Elle eut un petit hoquet vite éteint: elle battit un peu des ailes, doucement, un pauvre vieux corps! Elle pendait déjà inerte qu'il serrait encore éperdument. 
da pega. É por esse evento, exatamente pela morte do pássaro, que se revela o sentido da recusa do Odisseu de Giono à batalha com Antínoo, seu rival: longe de ser um pacifista, impressão que a resposta ao filho pode suscitar ("Sem guerra, sem guerra"), o Odisseu de Naissance de l'Odyssée é um covarde. Ele mata a pega pensando em evitar seu reconhecimento. A fiel afeição que lhe dedica a ave não é capaz de livrá-lo do pavor que lhe provoca a imagem de Antínoo. É o medo, portanto, o que o obriga a aniquilar "la seule qui se soit avancée sans faillir vers lui". Ele enforca o pássaro que lhe acariciava os dedos ao lembrar de seu temor contra o inimigo, deixando evidente não ser a ausência de desejo pela batalha o que lhe motiva a dizer "Sem guerra, sem guerra", mas, justamente, o medo do rival.

A escolha do pássaro pelo autor também não pode ser à toa. Giono compõe a passagem com um pássaro da família dos corvos, a pega [la pie], dos quais dá notícia em Écrits Pacifistes e em Le Grand Troupeau, nas muitas vezes em que se depara com corpos, nas rotas da guerra, com os "olhos comidos pelos pássaros" (GIONO, 2015, p. $20),{ }^{28}$ órgãos pelos quais eles têm conhecida preferência. A pega de Ítaca que, esperando o afeto de Odisseu, recebe dele a morte, não é, aliás, mencionada apenas nesta passagem. Quando pela primeira vez o Odisseu de Giono rememora a mentira que inventara na hospedaria e experimenta o medo lancinante da vingança dos deuses, pois "mais ele pensava, mais ele se sentia prisioneiro de sua mentira" (GIONO, 1938, p. 54) ${ }^{29}$ o que ele vê no horizonte do retorno não é senão um voo de pegas - para ele, um agouro nefasto.

Em Le Grand Troupeau, o corvo é, definitivamente, algo que desperta o medo dos combatentes. Joseph, uma das personagens que vai à guerra, tenta entender o porquê de o pássaro despertar o medo dos homens que vivem na guerra os piores horrores. Um de seus companheiros, ao ver um desses no horizonte grita: “- O corvo!", enquanto Joseph, fusil à mão, tenta acalmá-lo, ouvindo do amigo que lhe pedia para atirar na ave: "Eu tenho medo" (GIONO, 1931, p. 38) ${ }^{30}$ Ferido, o combatente assustado enxerga no pássaro o signo da

28 Texto original: aux yeux mangés par les oiseaux.

29 Texto original: plus il réfléchissait, plus il se sentait prisonnier de son mensonge.

30 Texto original: - Le corbeau!/ J'ai peur. 
morte. Joseph encoraja-o, promete-lhe proteção, mas o medo é maior, já que quem foi à guerra sabe que:

\begin{abstract}
Quando a luz da aurora estava ainda se desfazendo, os corvos chegavam a largos golpes de asas tranquilas. [...] Os corvos comiam o pão e ao mesmo tempo o recolhiam com duas garras saltando de uma pata para a outra. Depois, eles chegavam até a empurrar da cabeça o capacete do morto. Eram mortos frescos, às vezes ainda quentes, apenas um pouco pálidos. [...] Ali estava, bem doce e fresco, o sangue vermelho ainda fazia uma pequena bolha. Eles se punham a bicar para arrancar a pele, depois eles comiam seriamente, gritando de tempos em tempos para chamar as fêmeas. (GIONO, 1931, p. 116-7) $)^{31}$
\end{abstract}

Joseph, esse mesmo combatente de Giono em Le Grand Troupeau, além de ser quem se interroga sobre os corvos, é ainda aquele que se vale da invenção para fazer outro de seus companheiros se esquecer da dor. Ele faz o amigo ferido, com medo da pega, imaginar um domingo em que se ouve música, as mulheres são belas, e os dois põem-se na estrada, a caminho do baile da vila vizinha. Jules, o amigo entre a vida e a morte, conhece seu amigo e conhece a mentira, que é ali o melhor remédio: “- Eu sei, mentiroso! Conte devagar" (GIONO, 1931, p. 59). ${ }^{32}$

As falas falsas do protagonista de Jean Giono não são, apesar disso, mais do que um branco narrativo. $\mathrm{O}$ texto informa o leitor que Odisseu inventa uma grande história sobre si, mas apenas as personagens conhecem seu enredo; o leitor, não.

31 Texto original: Quand l'aube n'etait pas encore bien débarrassée, les corbeaux arrivaient à larges coups d'ailes tranquilles. [...] Les corbeaux mangeaient du pain et en même temps ils le vendangeaient de leurs griffes en sautant d'une patte sur l'autre. De là ils s'en venaient jusqu'à pousser de la tête le casque du mort. C'étaient des morts frais, des fois tièdes et juste un peu blêmes. [...] C'était là tendre et tout frais, le sang rouge y faisait encore la petite boule. Ils se mettaient à becqueter là, tout de suite, à arracher cette peau, puis ils mangeaient gravement en criant de temps en temps pour appeler les femelles.

32 Texto original: - Je sais, menteur! Parle doucemente. 
- Odisseu está ainda vivo e eis o que ele me contou nas margens do Eurotas...

Ele tossiu para limpar a garganta.

Por um momento as preocupações dos pássaros ressoaram entre as árvores.

Para além da floresta, o céu se enchia de uma areia de prata que estufava as estrelas. Enfim, uma lâmina ofuscante ultrapassou a redondeza negra da terra: as ondas suaves da noite começaram a borbulhar contra o arco da lua.

A voz de Odisseu ecoou por muito tempo entre os muros. $(\mathrm{GIONO}, 1938 \text {, p. 50) })^{33}$

No evento em que o Odisseu de Giono inventa sua grande história, ninguém o convida a se apresentar, não há o menor indício de que ele precisasse revelar sua identidade, ainda menos como prérequisito para que seu retorno pudesse se cumprir. Mas sua voz explode, sai de sua boca como se fosse dona de sua própria vontade, parecendo ter mais poderes sobre si do que ele mesmo sobre ela. Jean Onimus (1974) chama atenção para uma variante do texto em que o caráter mentiroso de Odisseu é, de certa forma, explicado por ele mesmo como o resultado de uma pulsão incontrolável. Nessa variante, Giono teria feito seu Odisseu dizer: "É mais forte do que eu, eu começo por dizer a verdade, mas depois minha língua se enrola e eu me percebo em plena mentira sem saber como" (GIONO, 1971, p. 887). ${ }^{34} \mathrm{O}$ recurso à mentira, evidenciado pela citação, mostra-se muito diferente em Naissance de l'Odyssée se comparado à Odisseia. Como a voz que explode boca afora, a mentira do Odisseu de Giono é mais forte que ele mesmo. Na Odisseia, a mentira de Odisseu é parte da sua força; ela compõe e comprova sua métis (DETIENNE;

33 Texto original: - Lui est toujours vivant, et voici ce qu'il me dit dans les caniers de l'Eurotas.../ Il toussa pour s'éclaircir la gorge. / Depuis un moment des inquiétudes d'oiseaux pépiaient au sein des arbres. Au-delà de la forêt, le ciel se poudrait d'un sable d'argent qui étouffait les étoiles. Enfin, un soc éblouissant dépassa la rondeur noire de la terre: l'onde molle de la nuit se mit à bouillonner contre l'étrave de la lune./ La voix d'Ulysse sonna longtemps contre les murs.

34 Texto original: C'est plus fort que moi, je commence par dire la vérité, puis ma langue fourche et je me trouve en plein mensonge sans savoir comment. 
VERNANT, 1974). É por dominar bem o que deve ser dito e o que não deve que o Odisseu de Homero é o herói mais astuto.

Ao inventar, diante do violeiro cego, um testemunho sobre si (Odisseu estaria vivo, teria sobrevivido a muitas aventuras como herói e estaria a caminho de casa), o Laertíade de Giono apresenta o eixo do romance: a mentira do retorno de Odisseu. De fato, a história do retorno do Odisseu francês centra-se não propriamente no retorno de Odisseu, mas na mentira de seu retorno. É verdade que, ao contar sua grande mentira, ele estava já a caminho de casa, mas Odisseu não é o mesmo daquele descrito pela mentira. Suas mentiras fazem surgir "uma nuvem de imagens novas" (GIONO, 1938, p. 53) $)^{35}$ e, por isso, a partir daí, elas vão se espalhar velozmente pelos quatro cantos, adiantando-se a ele não apenas em Ítaca. Sua mentira torna-se conhecida por violeiros da região, espécies de bardos, e alastra-se agilmente. A mentira de Odisseu tem, é claro, a força que faz com que a ficção e a mentira possam escapar da realidade, transfigurandoa, dando a ela um novo aspecto. Mas sua força parece extrapolar os limites, saindo totalmente fora do controle de seu criador.

Sua mentira se virava contra ele. Já não era uma única árvore na planície aberta, ao longe, mas um bosque de loureiros musicais, um bosque sagrado, uma enorme floresta, espessa, escura, viva, emaranhada de cipós e longos capins. Odisseu sentia subindo em torno dele o abraço dessa folhagem hostil. Ele soltou um suspiro profundo. $\mathrm{O}$ aedo, lisonjeado com a emoção, encheu-se de orgulho. (GIONO, 1938, p. 72) ${ }^{36}$

35 Texto original: une nuée d'images neuves.

36 Texto original: Son mensonge se dressait devant lui. Ce n'était plus l'arbre isolé sur la plaine rase, loin en arrière, mais un bosquet de lauriers musiciens, un bois sacré, une immense forêt, épaisse, noire, vivante, enchevêtrée de lianes et du tortillement des longues herbes. Ulysse sentait monter autour de lui l'étreinte de ces grandes frondaisons hostiles. Il poussa un profond soupir. L'aède, flatté de cette émotion se rengorgea comme un pigeon. 


\section{A permanência em Naissance de l'Odyssée}

Em Naissance de l'Odyssée a recusa do herói, sob a figura de um Odisseu médio, que só tem de herói o que contam suas mentiras, acontece por meio da evocação do herói arquetípico, o Odisseu grandioso de Homero. A métis admirável do Laertíade dá lugar, em Giono, ao medo. É a vez da supremacia da voz (que explode para dizer a mentira) sobre o pensamento, da vaidade sobre a inteligência. Mas esse novo Odisseu, que não incorpora as qualidades do herói tradicional, expõe o retorno da nova guerra pelo que a impediu de ser a guerra feita por heróis.

Como provoca Walter Benjamin em "Teorias do fascismo alemão. Sobre a coletânea Guerra e guerreiros, editada por Ernst Jünger"37, frases dos combatentes Batalha do Marne e de Verdun, até então inimagináveis, tais como: "Conduzimos a guerra segundo princípios impuros"; ou "Tornou-se cada vez mais raro combater de homem a homem e tropa contra tropa"; ou "Muitas vezes os oficiais da linha de frente conduziram a guerra sem qualquer estilo"; e até "Com a incorporação, no corpo dos oficiais e dos suboficiais [...] do homem comum, os elementos eternamente aristocráticos da atividade militar foram sendo crescentemente abolidos" (BENJAMIN, 1994, p. 63-64) não revelariam mais do que uma percepção confusa da guerra, em que a nova guerra, a guerra de material, entra em confronto com a guerra tradicional, feita por heróis e por valores como a honra e a glória. Benjamin acusa esses combatentes de terem, por meio de seus registros, cultuado a guerra, exatamente porque, ao registrarem suas mudanças ou seu novo caráter, eles teriam demonstrado a necessidade ou a vontade de retomar o modelo tradicional de guerra, em que "valores puros", "combates verdadeiros" e "estilo de guerra" determinariam sua imagem, salvando-a da degeneração. Em suma, a guerra teria se transformado e teria transformado também os combatentes entusiastas de 1914 em soldados desencantados logo após os primeiros meses do conflito, mas a consequência dessa

37 Neste texto de 1930, Benjamin critica, justamente, combatentes que, como Ernst Jünger, evocam o ideal de guerra nobre em busca de criticar a guerra vivida. 
transformação, perceptível nos registros dos combatentes, segundo a crítica de Walter Benjamin, teria sido, no entanto, não a refutação da guerra, nem a refutação do heroísmo na guerra, mas a refutação da guerra de material em que o herói, a glória e a honra não têm vez.

É ainda Walter Benjamin quem, em textos da década de 30, como "Experiência e Pobreza" e "O Narrador", observa que a violência da nova guerra, sobretudo a violência das trincheiras, teria levado os homens a perderem a capacidade de intercambiar a experiência. No mundo tradicional, que desconhecia a trincheira e a guerra de material, a sabedoria servia aos outros, a experiência passava de pessoa a pessoa. Essa experiência, porém, teria chegado ao fim exatamente com a geração que vivera, de 1914 a 1918, um dos eventos mais assustadores da história universal. Jamais, até então, experiências adquiridas haviam sido tão radicalmente desmentidas, como a experiência da guerra de ataque pela guerra de defesa, a experiência econômica pela inflação, a experiência corpórea pela prova da fome, a experiência moral pela manobra dos governantes. Com a Grande Guerra, uma geração que havia ido à escola em tramway volta à sua origem encontrando paisagens que em muito pouco se permitem reconhecer. No mundo das trincheiras e do gás tóxico, a arte teria passado, por isso, a incorporar ou a se nutrir, no lugar da experiência, apenas da dúvida (BENJAMIN, 1994, p. 114-115).

A experiência da Grande Guerra é, enfim, radicalmente desmentida em seu teor de conhecimento e de verdade e a geração que a conhece passa a duvidar, como Jean Giono, do herói e do lado épico da verdade. É o assustador desenvolvimento da técnica que dá à guerra essa nova imagem. A partir da guerra, a primeira grande guerra do século $\mathrm{XX}$, o homem volta à pátria completamente empobrecido: empobrecido até mesmo em termos de experiência. E isso não significa que o combatente volta, posto que esvaziado de experiência, em busca dela. A Grande Guerra faz com que os combatentes retornem ingurgitando a experiência, a cultura e o homem.

Walter Benjamin (1994) não está dizendo, obviamente, que nada seja dito sobre a guerra. Em 1931, quando Gaston de Pawlowski analisa Le Grand Troupeau de Jean Giono e diz que o público já está enfarado de "livros sobre a guerra", o crítico considera Le Grand Troupeau apenas mais um a se somar ao número já considerável de romances (na França, sobretudo romances) cujo tema é a Grande 
Guerra. O que Benjamin, por outro lado, observa é a maneira pela qual a Grande Guerra destrói a experiência em sua dimensão comunicável e, como consequência, passa a ser investida na arte do romance, que incorpora as questões irrespondíveis pelo vivido, a incerteza e, em Jean Giono, a mentira.

Em carta a Jean Carrière, Giono diz precisamente que a guerra o satisfazia enquanto evento. $\mathrm{O}$ que havia sido escrito tratava não do que havia existido, mas do negativo da experiência: “(...) o evento em si apresentava-se tão interessante que eu não tinha vontade alguma de escrever a coisa" (GIONO apud CARRIÈRE, 1985, p. 142). ${ }^{38}$

A relação de Jean Giono com a guerra, quando descrita em suas cartas (em especial nas cartas enviadas aos pais, Jean-Antoine e Pauline Giono), é uma relação de exterioridade. São comuns as expressões que o distanciam do perigo, do risco e da morte, tais como: "eu não arrisco absolutamente nada", ou ainda, "eu não vou em direção ao perigo, isso é o que é verdade"; 39 "é muito interessante e parece que estou em meio à leitura de um ótimo livro"; "40 "daqui, nós não diríamos mais que estamos em guerra". ${ }^{41}$ Fica muito evidente para o leitor de sua correspondência que o autor quer poupar os pais das preocupações, minimizando os perigos, embelezando o confronto e, insistentemente, criando uma atmosfera de bem-estar e conforto. A estratégia que ele usa para fazer isso é reveladora do ponto de vista de sua relação com a verdade e a mentira. Jean Giono descreve, para os pais, seus dias na guerra como dias de prazer e deleite. O chocolate quente é delicioso, a cama é confortável, o clima é bom, o uniforme, além de dado pelo governo, é muito bonito, os exercícios são excelentes, o aprendizado gratificante, seus companheiros são os melhores, suas expectativas ainda mais. O front está sempre longe, o risco nunca se aproxima. E se qualquer perigo o ameaça, a mentira e a dissimulação podem lhe servir de ferramentas:

38 Texto original: (...) l'événement lui-même présentait assez d'intérêt pour que je n'aie envie d'écrire la chose.

39 Texto original: je ne risque absolument rien ou ainda je ne vais pas au danger, c'est que c'est vrai.

40 Texto original: c'est très intéressant et il me semble que je suis en train de lire un joli livre.

41 Texto original: ici on ne dirait plus qu'on est en guerre. 
Eu fui felicitado nesta manhã pelo adjunto e pelo tenente que me encarregou de ensinar a marchar dois ou três dos meus colegas (que são de Valensole). Vocês adivinhem se estou orgulhoso. Estou um pote de orgulho. Eu mostro muita boa vontade por ora, isso os deixa satisfeitos. Mas, depois, nas caminhadas ou nas lutas com baionetas, eu recuarei. E então, eles vão dizer, "enquanto ele pôde fazer, ele fez muito bem, e, agora, se ele não o faz, é porque ele não pode, pois sempre mostrou boa vontade", e aí será o momento de ficar doente. (Carta de Jean Giono JeanAntoine e Pauline Giono. Montsegur, [quinta-feira] 23 de setembro de 1915). (GIONO, 2014-2015, p. 56) ${ }^{42}$

Para Jacques Mény (2014-2015), que apresenta a Correpondência 1915-1919 de Jean Giono, taxar o procedimento do autor como mentira ou afabulação seria, no entanto, não o compreender. Segundo Mény, Giono apenas selecionaria e valorizaria os elementos que, embora possam parecer distantes aos olhos de quem recebe suas cartas, são, ainda assim, plausíveis. Por outro lado, Pierre Citron (1971), que conhecia o amigo, explica, porém, o quanto era de sua preferência o prazer de uma mentira à monotonia das verdades cruas.

Provavelmente, no sanatório do Doutor Paul-Émile Davy (1888-1963), inaugurado em 1926, em Plateau d'Assy, na região da Savoia, Jean Giono lê para alguns ouvintes trechos das aventuras do seu Odisseu, intercalando, à leitura dos fragmentos, comentários sobre a história e sua participação na Grande Guerra. Ao falar sobre Naissance de l'Odyssée para seus pares, homens que, como ele, tinham ido à guerra, Giono quis deixar claro que o seu Odisseu era "irmão deles" ["leur frère"] (GIONO, 2004, p. 15). Como o de Homero, ele explica, seu herói era também um combatente que

42 Texto original: J'ai été ce matin félicité par l'adjudant et le lieutenant qui m'a chargé d'apprendre à marcher à deux ou trois de mes collègues (qui sont de Valensole). Vous pensez si je suis fier, hein. Je suis un poisson. Je montre beaucoup de bonne volonté pour l'instant, cela leur fait plaisir. Mais, par la suite, dans les marches ou l'escrime à la bä̈onnette, je canerai. Alors ils diront: "quand il pouvait le faire, il le faisait très bien et maintenant, s'il ne le fait pas, c'est qu'il ne peut pas, puisqu'il a toujours montré de la bonne volonté" et alors ce sera le moment d'être malade. (Lettre Jean Giono à Jean-Antoine et Pauline Giono. Montségur, le [jeudi] 23 septembre 1915). 
demorara a retornar, mas que, diferentemente daquele, não possuía a proteção dos deuses, nem qualidade alguma. Seu Odisseu era um Odisseu humano, parecido com qualquer um, à altura de qualquer um e que, como todos ali, tremera de medo na guerra:

De tanto me ver em caminhos familiares em meio ao povo de minha terra, eu não mais imaginava [Odisseu] coberto de seu capacete e de seu ardil divino, mas eu o via parecido com aqueles que eu conheci nos campos de oliveiras. Eram homens que voltavam da guerra, como eu, como ele. Eu encontrava nele um coração humano, frágil e trêmulo. Eu o via à minha altura, à nossa altura comum. É desse longo contato com essa confiança risível, e essa crueldade da juventude, que nasce sua história longe dos deuses. (GIONO, 2004, p. 13) (3 $^{2}$

Nesta conferência, o autor parece estar realmente disposto a admitir os dois retornos em seu romance: enquanto Odisseu voltava a Ítaca, sendo o rei, dono de posses; Giono, por sua vez, "miserável soldado, sem nada a reconquistar, nem mulher, nem terra" (GIONO, 2004 , p. 19),${ }^{44}$ voltaria para a casa onde o esperavam os velhos pais. Jean Giono quis, com sua fala, sobrepor sua experiência real do retorno da guerra à experiência fictícia de Odisseu, sem deixar de realçar que a sua experiência havia sido mais pobre, mais triste e mais difícil. Ele quis, em função da sua própria experiência, reinventar Odisseu para que só então, porque reinventado, ele pudesse comunicar o que havia sido a experiência da guerra, "a nova guerra de

43 Essa conferência, publicada apenas em 2004, permaneceu por muito tempo desconhecida e sua data é incerta (Laurent Fourcault propõe o ano de 1934). O texto da conferência é dedicado ao médico, especialista no tratamento de tuberculosos, que havia decidido cuidar em seu sanatório, sobretudo, de ex-combatentes da Grande Guerra portadores da doença. Texto original: $\dot{A}$ force de le voir avec moi dans les chemins familiers au milieu des habitants de ma terre, je ne l'imaginais plus couvert de son casque et de sa ruse divine mais je le voyais semblable à ceux que je rencontrais dans les vergers d'oliviers. C'étaient des hommes qui revenaient de la guerre, comme moi, comme lui. Je lui trouvais un coeur humain, frêle et tremblant. Je le voyais à ma mesure, à notre commune mesure. C'est de ce long contact avec cette confiance risible, et cette cruaté de la jeunesse - son histoire en dehors de dieux.

44 Texto original: humble soldat, n'ayant rien à reconquérir, ni femme, ni domaine. 
Troia". Para que ele conservasse o amor pelas mulheres, pela pátria e pela mentira, mas não "seu capacete e de seu ardil divino", era preciso que seu Odisseu não fosse um herói.

Em seu "Je ne peux pas oublier" ["Eu não posso esquecer"], o ex-combatente escreve: "Na guerra, eu tenho medo, estou sempre com medo, eu tremo, eu faço nas calças" (GIONO, 2015, p. 19). ${ }^{45}$ Com efeito, numa das variantes de Naissance de l'Odyssée, o Odisseu de Giono conta para os hóspedes da estalagem que, embora tivesse ido à guerra da Ásia, ele havia, antes de partir para o combate, tentado fugir dela por medo, pois "a coragem não é dom de todo mundo":

"Eu escondi-me para não ir à guerra. O que você queria? A coragem não é dom de todo mundo. Em Troia, você sabe, eu não fiz grande coisa. Aqueles troianos eram uns baitas animais! Se você tivesse visto o pobre-coitado do Pátroclo! Trucidado! Essas coisas me fazem mal. Se eu tivesse força suficiente, você veria, eu teria empurrado minha nau pelas ondas e teria partido." (I, 29, var. a da p. 40 - GIONO, 1971, p. 887 $)^{46}$

A odisseia de Giono ou a mentira de seu Odisseu nasce, assim, não sem motivo, como sugere François Cyrille (2008), ou pelo simples gosto pela mentira, mas para evidenciar, pela descoberta do que é guerra, que o novo Odisseu retorna dela sem ser o herói esperado. O Odisseu de Giono não quis ir à guerra, não quis permanecer na guerra e, lá, não fez grande coisa. É por isso que, em seu retorno, ele só terá feitos para serem contados se os inventar. Esse Odisseu não mistura mentiras a verdades, nem se reconhece nas histórias. Ele apenas mente e reconhece, nos cantos, suas palavras falsas. Diferentemente dos combatentes a quem Walter Benjamin

45 Texto original: À la guerre j'ai peur, j'ai toujours peur, je tremble, je fais dans ma culotte. 46 Texto original: "Je me suis caché pour ne pas partir à la guerre. Que veux-tu, le courage n'est pas le lot de tout le monde. Eh! À Troie, tu sais, je n'ai pas fait grand-chose. C'était de belles brutes, ces Troyens! Si tu avais vu ce malheurex Patrocle! Écrabouillé! Ah! Ces choses-là me faisant mal. Si j'avais eu assez de force, vois-tu, j'aurais poussé mon bateau jusqu'à l'eau libre et je serais parti." 
criticou, diferentemente daqueles que sentiram a falta dos heróis na guerra, Jean Giono escolheu o maior herói da tradição para dizer, através de sua grande mentira, exatamente aquilo que lhe parecia a verdade: o herói é a grande mentira, que soube atravessar os tempos e permanecer na história. Giono eleva a mentira, insiste na mentira para expor o herói, para desmascará-lo, para desmascarar a guerra. Sua solução, porém, é ainda recorrer ao herói. Naissance de l'Odyssée, mostrando quão frágil é essa permanência, revela também que não é possível livrar-se dela tão facilmente.

\section{Referências bibliográficas}

BENJAMIN, Walter; ROUANET, Sergio Paulo; GAGNEBIN, Jeanne-Marie. Magia e técnica, arte e política: ensaios sobre a literatura e história da cultura. 7ª ed., São Paulo: Brasiliense, 1994.

BENJAMIN, Walter. Oeuvres II. Paris: Éditions Gallimard, 2000 BÉRARD, Victor. Dans le Sillage d'Ulysse, Album Odysséen (photographies de Frédéric Boissonas). Paris: Librarie Armand Colin, 1973.

BÉRARD, Victor. La Résurrection d'Homère. Paris: B. Grasset, 1930.

BÉRARD, Victor. Les Navigations d'Ulysse. 4v. Paris: Librarie Armand Colin, 1971.

BÉRARD, Victor. Les Navigations d'Ulysse I - Ithaque et la Grèce des Achéens. Paris: Librarie Armand Colin, 1927a.

BÉRARD, Victor. Les Phéniciens et l'Odyssée. Paris: Librarie Armand Colin, 1927b.

BÉRARD, Victor (trad). L'Odyssée: "poésie homérique". (18641931). 3 vol. Paris: les Belles Lettres, 1924.

BRANDÃO, Jacyntho José Lins. Como se deve escrever a história. Ed. bilingue. Belo Horizonte: Tessitura, 2009. 
CARRIÈRE, Jean. Jean Giono, coll. "Qui êtes-vous". Lyon: La Manufacture, 1985, p. 142.

CITRON, Pierre. Le recentrage de Giono à partir de 1939. Études littéraires, vol. 15, n. 3, 1982, p. 441-57.

DABDAB TRABULSI, J. A. L'Antique et le Contemporain. 1. ed. Besançon/França: PUFC, 2009.

DABDAB TRABULSI, J. A. La "cité grecque" positiviste. Anatomie dún modède historiographique. 1. ed. Paris: L'Harmattan, 2001.

DABDAB TRABUlSI, J. A. Le Présent dans le Passé. 1. Ed. Besançon: PUFC, 2011.

DETIENNE, Marcel, VERNANT, Jean-Pierre, Les ruses de l'intelligence. La «mètis » des grecs, Paris: Flammarion, 1974.

GENETTE, Gérard. Palimpsestes: la littérature au second degré.

GIONO, Jean. Accompagnés de la flûte. Lettres à Lucien Jacques/ Jean Giono / [Illustrations ] de Lucien Jacques. Manosque: Éditeur Manosque, 1959.

GIONO, Jean. Revue Giono. N. 8 - 2014-2015. Association des Amis de Giono. Manosque.

GIONO, Jean. Écrits pacifistes: Refus d'obéissance; Précisions; Recherche de la purété. Paris: Gallimard, 2015.

GIONO, Jean. Une conférence-lecture de Giono sur Naissance de l'Odyssée. In: FOURCAULT, Laurent [éd.]. Bulletin de l'Association des Amis de Jean Giono, n 62, Manosque, automne-hiver 2004, p. 7-24.

GIONO, Jean. Naissance de l'Odyssée. Paris: Éditions Grasset e Fasquelle, 1938.

GIONO, Jean. Le Grand Troupeau. Paris: Éditions Gallimard, 1931.

GIONO, Jean. Jean Giono. Euvres romanesques complètes. Tome I. Édition de Robert Ricatte avec la collaboration de Pierre Citron, Henri Godard, Janine et Lucien Miallet et Luce Ricatte.. Paris: Éditions Gallimard, 1971. 
Homeri Ilias, vols. 2-3, Ed. Allen, T.W. Oxford: Clarendon Press, 1931. Homeri Odyssea, Ed. Peter von der Mühll, P. Basel: Helbing \& Lichtenhahn, 1962.

HOMERO. Ilíada. Tradução de Frederico Lourenço. São Paulo: Penguin Classics; Companhia das Letras, 2013.

HOMERO. Odisseia. Tradução de Frederico Lourenço. São Paulo: Penguin Classics; Companhia das Letras, 2011.

JOUANNO, Courinne. Ulysse: Odyssée d'un personnage d'Homère à Joyce. Paris: Ellipses Édition Marketing S. A., 2013.

MÉNY, Jacques. Jean Giono. Correspondance 1915-1919: présentation. Revue Giono. N 8 - 2014-2015. Association des Amis de Giono. Manosque, p. 11-33.

PAWLOWSKI, Gaston. Gringoire, 18 de décembre, 1931, p.4, citado por Michel Gramain, Le Grand Troupeau (Étude de réception), p. 232. In: Revue Giono. N 8 - 2014-2015. Association des Amis de Giono. Manosque.

SAIID, "Ulysse en France au début du XXe siècle: de Giraudoux à Giono", p. 395. In: Ulisse nel tempo. La metafora infinita. Atti del Convegno internazionale Odisseo 2000. Venezia, 2003, p. 379-403.

SILVA, Glaydson José da. História Antiga e usos do Passado. Um estudo de apropriações da Antiguidade sob o regime de Vichy (19401944). São Paulo: Annablume; FAPESP, 2007. 